\title{
The gender-marking effect in spoken word recognition
}

\author{
FRANÇOIS GROSJEAN, JEAN-YVES DOMMERGUES, ETIENNE CORNU, \\ DELPHINE GUILLELMON, and CAROLE BESSON \\ University of Neuchâtel, Neuchâtel, Switzerland
}

\begin{abstract}
In this paper we examine whether the recognition of a spoken noun is affected by the gender marking-masculine or feminine - that is carried by a preceding word. In the first of two experiments, the gating paradigm was used to study the access of French nouns that were preceded by an appropriate gender marking, carried by an article, or preceded by no gender marking. In the second experiment, subjects were asked to make a lexical decision on the same material. A very strong facilitatory effect was found in both cases. The origin of the gender-marking effect is discussed, as well as the level of processing involved-lexical or syntactic.
\end{abstract}

Has there been a nonnative speaker of a language such as French, Italian, Spanish, German, or Russian who has not been admonished for occasionally using the wrong gender marking? It is common to hear the student of French, for example, being told, "No, it's not un table, it's une table," or the student of German being corrected with, "It's not das Lampe, it's die Lampe." At first, one might think that the person doing the correcting is only being a stringent defender of the language being spoken, but repeated corrections, even by nonnormative speakers, lead one to think that perhaps there is more to the admonishment than just purism. Could it be that native speakers of languages that have gender agreement actually use gender markings (found with articles, pronouns, adjectives, verbs, etc.) during lexical access? If that were the case, incorrect gender markings by a nonnative speaker may actually produce an incorrect set of word candidates. The consequence would be delayed recognition at best and misperception at worst. The aim of the present study was to examine whether gender marking plays a role in spoken word recognition and, if so, what the nature of this effect is.

It is well known that certain languages are characterized by gender, which can be defined as follows:

A subclass within a grammatical class (as noun, pronoun, adjective, or verb) of a language that is partly arbitrary but

\footnotetext{
This study was supported in part by Grant 12-33582.92 from the Swiss National Science Foundation. The authors would like to thank Lysiane Grosjean for recording the sentences, Jane Wozniak-Webster for help with the data analysis, Ken Forster, Maryellen MacDonald, and Patrizia Tabossi for interesting discussions concerning the gendermarking effect, as well as Gary Dell, Jim Gee, Jacqueline GremaudBrandhorst, Corinne Tschumi, and Cornelia Tschichold for their comments on earlier versions of the paper. Very special thanks go to Joanne Miller and two anonymous reviewers for their help during the revision process. J.-Y.D. is also at the Laboratoire de phonétique, University of Paris VII. Address correspondence to F. Grosjean, Laboratoire de traitement du langage, Université de Neuchâtel, Avenue du PremierMars 26, 2000 Neuchâtel, Switzerland.
}

also partly based on distinguishable characteristics (as shape, social rank, manner of existence, or sex) and that determines agreement with and selection of other words or grammatical forms. (Webster's Ninth New Collegiate Dictionary, 1991)

A first point to stress is that, depending on the language, words (usually nouns) carry one of a number of genders-for example, two for French, Italian, and Spanish, three for German and Russian, and six for Swahili (Corbett, 1991). Gender type has often been divided into two parts: "natural" and "grammatical" gender. "Natural" gender refers to the fact that some semantic properties, which vary considerably from one language to another, dictate the gender category of a word. Among these are sex, shape, texture, color, animacy, edibility, and so on. There are other bases for attribution of "grammatical" gender-for example, the phonotactics of the word or of its parts, or the vowel it contains. A second point of importance is that other word classes in a language that includes gender, such as adjectives, verbs, articles, pronouns, and so on, do not have a gender per se, but can reflect, in their inflectional morphology, the gender of the words that do. Thus, table is feminine in French, and in the phrase "une petite table blanche" (a small white table), the article une and the adjectives petite and blanche all agree with the noun and hence carry a feminine gender marking (italics in the example). It should be noted that the agreement marking (which we will call gender marking) can appear before or after the noun, as well as close to it-as in the example above-or at a certain distance from it. For example, in the sentence, "Construite au début du siècle, cette table est un chef-d'oeuvre" (Built at the turn of the century, this table is a masterpiece), the feminine inflection on construite announces a feminine noun (table) that occurs six words later in the sentence.

In this paper, we will study the recognition of nouns in spoken French that are preceded by a gender marking. Although an increasing number of researchers have in- 
vestigated spoken word recognition in French (see, e.g., Cutler, Mehler, Norris, \& Ségui, 1986; Radeau \& Morais, 1990; Radeau, Mousty, \& Bertelson, 1989; Ségui, 1989a, 1989b; Ségui, Dupoux, \& Mehler, 1990; Wioland, Brock, \& Metz-Lutz, 1990), none have concentrated specifically on the role of gender marking. ${ }^{1}$ In a first experiment, we used the gating paradigm (Grosjean, 1980) to examine the effect. This paradigm presents a number of advantages that make it a useful tool in the study of the word recognition process. First, it allows one to assess how much of a word is needed to be identified or "isolated" correctly. This is done by determining a word's isolation point, which is quite close to the word's uniqueness point when the word is heard out of context (Tyler \& Wessels, 1983, 1985), and which corresponds quite closely to what Bradley and Forster (1987) mean when they say that a word has been "accessed." A second advantage of the paradigm is that one can examine the confidence ratings proposed by listeners at various points in time. A third advantage is that the word candidates proposed before the isolation point give some insight into the word-isolation process itself. Because the on-line nature of the gating paradigm has been questioned, ${ }^{2}$ and in order to bring converging evidence to the results found in the first experiment, we conducted a second experiment, using a lexical decision task.

The experiments were undertaken to help us answer the following question: Does gender marking affect the lexical access of words in French? More specifically, does the gender marking carried by an article (e.g., feminine "la" in "la table," masculine "le" in "le croissant") affect the recognition of the following noun? In terms of the gating paradigm, will the isolation points, the confidence ratings, and the proposed candidates be affected by the presence or absence of the article? And in terms of lexical decision, will reaction times be different in these two conditions? We will show not only whether gender marking has an effect on word recognition, but also whether or not this effect is facilitatory. We will do this by comparing the presence of a gender marking with its absence - the baseline condition. This condition is frequently found in the language - for example, when a noun is preceded by a plural determiner or a determiner that does not carry gender information or, simply, by no determiner at all. We will end our study by discussing the origin of the effect and the level of processing involved. Is it purely a lexical effect, or does it also involve the syntactic level?

\section{EXPERIMENT 1}

In this experiment, subjects were presented with nouns that were preceded either with an appropriate gender marking (carried by an article) or with no gender marking (absence of the article). Their responses (isolation points, confidence ratings, and word candidates) were examined and interpreted in terms of the questions raised previously.

\section{Method}

Subjects. Twenty-four native, French-speaking students of the University of Neuchâtel (Switzerland), with no reported speech or hearing defects, served in the study.

Materials. Twenty-four French nouns-12 masculine and 12 feminine - were chosen for the study (see the Appendix for a complete list). Half of the words in each set were one syllable long, and the other half were two syllables long. Care was taken to make sure that the two sets of nouns had the same mean frequency of occurrence ( 31.0 for the masculine words and 30.6 for the feminine words, based on the Juilland, Brodin, \& Davidovitch, 1970, frequency count). Their uniqueness points were also similar: for each set, six were situated on the second to last or last phoneme, and six were situated beyond (Le Robert Oral-Ecrit, 1989; BRULEX database, Content, Mousty, \& Radeau, 1990). Every word except for one (tissu) had a gender-uniqueness point that was similar to its normal uniqueness point. (The gender-uniqueness point is based solely on nouns that share the same gender.) Finally, it was necessary for each word to be able to be preceded by the adjective joli (e) (best translated here as "nice").

The words were embedded in the sentence, "J' ai vu un(e) joli(e) samedi" (I saw a nice on Saturday); the 24 sentences obtained this way were recorded at a normal rate by a native speaker of French. The recordings were digitized at a sampling rate of $20 \mathrm{kHz}$ and gated with a waveform editing program developed on a PDP 11/23 at the University of Neuchâtel. For each sentence, the onset of the stimulus word was located as precisely as possible by inspecting the speech waveform and by using auditory feedback. Most of the stimulus words began with a stop consonant or a fricative, so their onsets corresponded, respectively, to the end of the silence preceding the release burst and to the start of the frication in the speech wave.

Two groups of gated stimuli were prepared. In the first, and for each of the 24 experimental words, the gated sequences were preceded by the adjective joli $(e)$ only. ${ }^{3}$ For a particular word set, then, the first gate contained joli $(e)$ and $0 \mathrm{msec}$ of the experimental word. The second gate contained joli (e) plus the first $60 \mathrm{msec}$ of the word; the third gate contained joli $(e)$ plus the first $120 \mathrm{msec}$ of the word, and so on. Gate lengths were increased by $60 \mathrm{msec}$ until the end of the word was reached. When the duration of the stimulus word was not an exact multiple of 60 , the last gate was increased by $60 \mathrm{msec}$ plus the amount needed to reach the end of the word. This procedure was also used for the second group of stimuli, except the word segments were preceded not only by the adjective before the noun but also by the article (un[e]) preceding the adjective. Although joli $(e)$ by itself carries no overt phonetic information about the gender of the following noun, "un" or "une" clearly indicate whether the noun after the adjective is masculine or feminine. Thus, the only difference between the two groups of stimuli was that one contained gender information carried by the article, and the other did not. The phonetic forms of the adjectives and the nouns were identical in the two groups. Gating sets for each word were prepared as in the first group of stimuli, and then two experimental tapes were made — one for each group. On each tape, word sets were separated by a pause of $15 \mathrm{sec}$ and announced by a tone; stimuli within sets were separated by a pause of $5 \mathrm{sec}$.

Procedure. The subjects were split into two groups of 12 . One group was run on the first tape (where gender marking was absent), and the other was run on the other tape (gender marking was present). The subjects were run individually. They were asked to listen to the presentations and to do two things afterward: (1) write down the word they thought was being presented after either "joli(e)" or "un(e) joli(e)," depending on the tape they were listening to, and (2) indicate how confident they were by circling a number on a scale of 1-10 (anchored with très incertain [very unsure] and certain [sure]). They were asked to give a response after every presentation, regardless of how unsure they might have felt about the stimulus word. 
Data analysis. The subjects' response sheets provided three kinds of information. The first concerned the isolation point of a word - that is, the point (expressed in milliseconds) at which the subject correctly proposed the stimulus word and did not subsequently change his or her mind. This point was located for each word and each subject and was converted into a percent of the way through the word - that is, a percentage of the word that had to be heard for it to be isolated. The second concerned the confidence rating at the last gate. For each measure, missing values were replaced by the mean calculated over subjects. They represented $3.1 \%$ of all the isolation-point data and $3.5 \%$ of the confidence ratings. Global means were calculated for both measures, and simple $t$ tests were then used to compare the results of the two groups of subjects. Finally, the erroneous candidates proposed prior to the isolation point were analyzed with respect to type and number as a function of the way through the stimulus word (WTW).

\section{Results and Discussion}

Isolation points and confidence ratings. Figure $1 \mathrm{~A}$ presents the amount of a word needed to isolate it as a function of the absence or presence of gender marking ("un" for masculine words, "une" for feminine words). As can be seen, to isolate a word, the listeners needed, on average, more of the word when gender marking was absent than when it was present $[59.83 \%$ and $50.75 \%$, respectively; by words, $t(23)=2.91, p<.01$; by subjects, $t(22)=5.26, p<.001]$. In addition, the confidence ratings at the ends of words were different in the two conditions (Figure 1B). The subjects were less confident when gender marking was absent than they were when it was present $[9.3$ and 9.8 , respectively; by words, $t(23)=$ $2.31, p<.05$; by subjects, $t(22)=3.61, p<.01]$. Thus, gender marking appears to affect the lexical access of words (more specifically, of nouns) and, in so doing, it joins a number of other factors that account for the time it takes to identify a word.

Because a possible artifact could explain these results, we conducted a control study with a limited set of words. This potential artifact was that the gender effect could be due not so much to the presence of a gender marking in the article, but to the fact that the subjects in that group heard more acoustic/phonetic and, especially, prosodic information than did the group without the gender marking (three syllables and two words vs. two syllables and one word, respectively).

In order to make sure that this artifact was absent, we ran a short control study. Twenty-four subjects were presented with eight of the words from the original study, which were recorded in the sentence "J'ai vu de joli(e)s samedi" (I saw some nice on Saturday). Here, the article "de" carries no gender information on the following noun. Two groups of gated sequences were prepared, as in the main experiment. In the first, "de" preceded joli(e)s, but in the second it did not. The experimental procedure was the same- 12 subjects heard the first tape, and 12 heard the second. The results showed that the main findings of our study were not due to an artifact. The mean isolation points were not different when "de" was absent or present $[62.7 \%$ and $65.4 \%$, respectively; by words, $t(7)=1.33$, n.s.; by subjects, $t(22)=0.62$, n.s.], and the confidence ratings
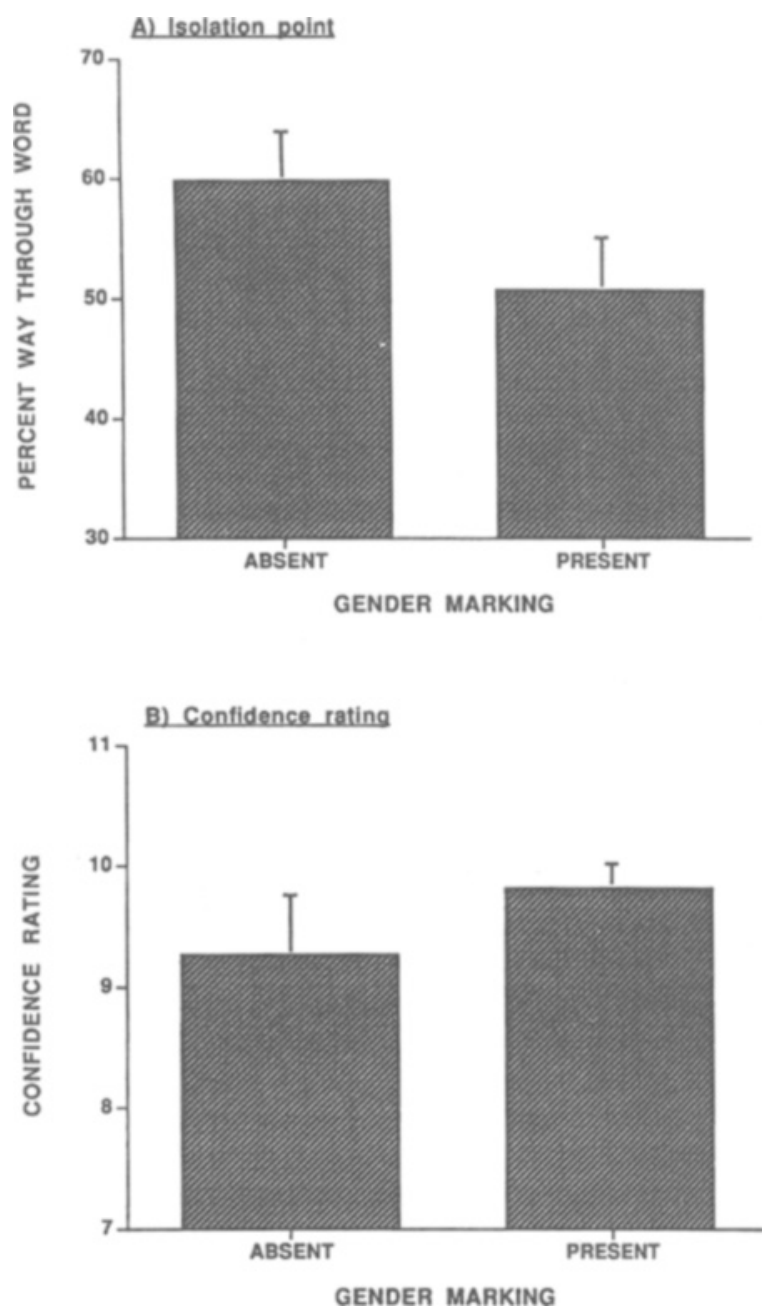

Figure 1. Amount of a word (expressed as a percentage of the way through the word) needed to isolate it (top panel, A) and confidence rating at the end of a word (bottom panel, $B$ ) as a function of the absence or presence of gender marking. Each mean is based on $288 \mathrm{ob}-$ servations. Error bars represent +1 standard deviation.

were not different at the ends of the words [9.0 and 9.3, respectively; by words, $t(7)=1.62$, n.s.; by subjects, $t(22)=1.05$, n.s.].

Word candidates. The gender-marking effect is clearly apparent when one examines the proposed candidates under the two experimental conditions. Figure 2 presents the candidates for the feminine word plage (beach) at each gate in the two conditions. Candidates that share a gender with the stimulus word (feminine) are in uppercase, and candidates that were proposed by 3 or more subjects are in bold. Items for which no gender classification could be made (no answers, $\varnothing$, incomplete words, nonwords, etc.) are in italics. We observe that when gender marking is absent (top part of the figure), there is a steady onset-to-offset "narrowing in" on the stimulus word, and that some candidates, other than plage, were proposed quite often (e.g., plat and plateau). What is interesting is that, given the lack of gender information 
Gender marking absent

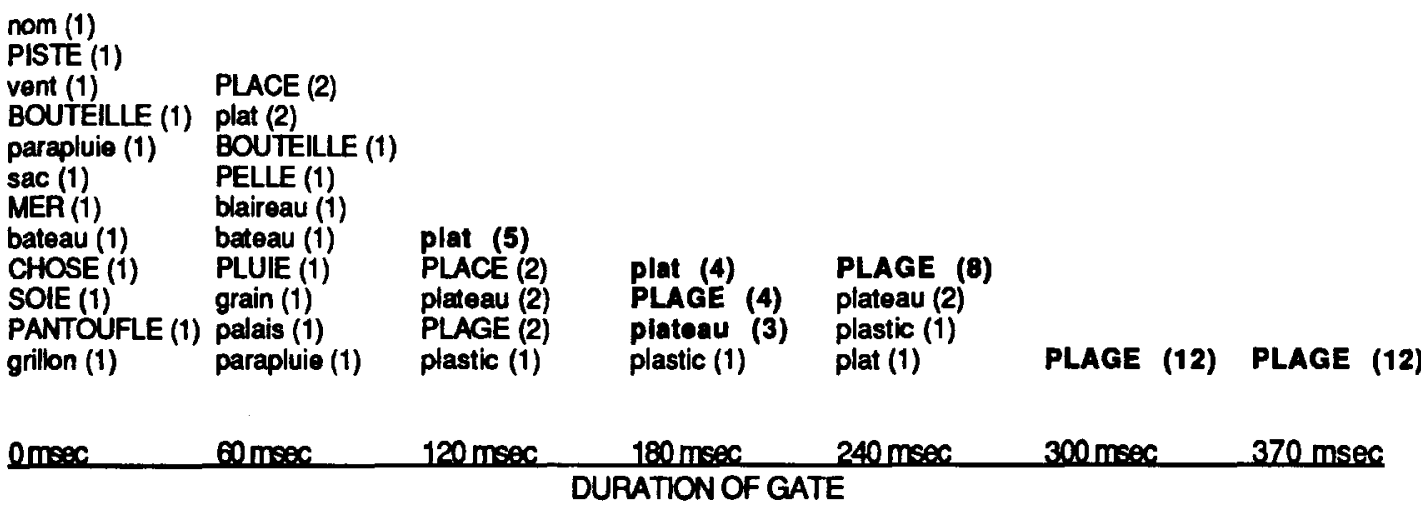

\section{Gender marking present}

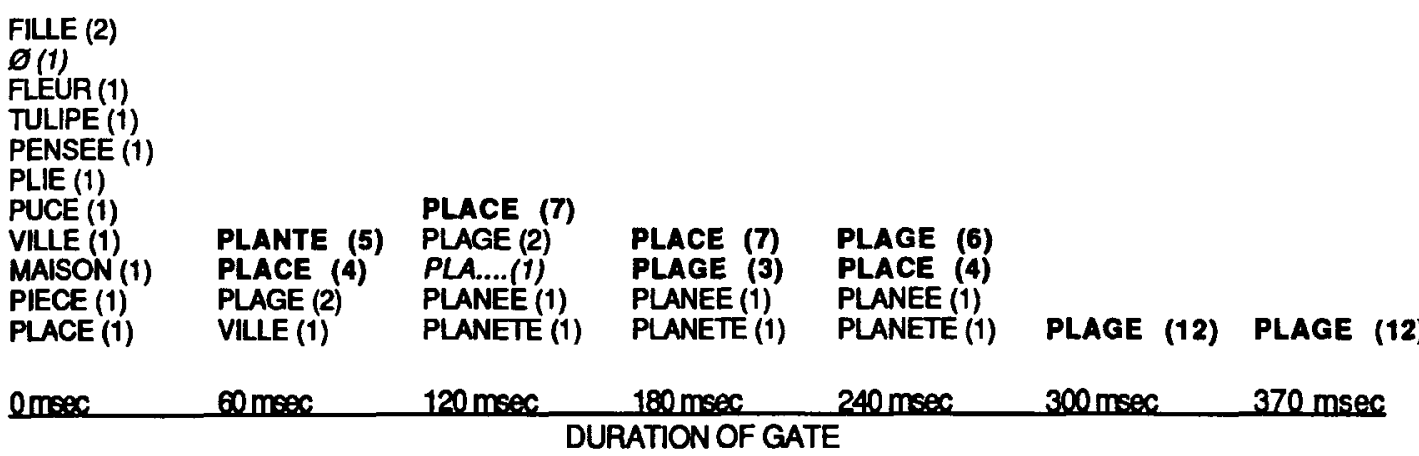

Figure 2. Candidates proposed for the feminine word plage (beach) at each gate when gender marking is absent (top) and present (bottom). Candidates that share the same gender as the stimulus word (feminine) are in uppercase, and candidates that were proposed by 3 or more subjects are in bold. Items for which no gender classification could be made (no answers, $\theta$, incomplete words, nonwords, etc.) are in italics. The results are based on 12 subjects.

preceding the stimulus word, the candidates belong to either the masculine or the feminine gender, depending on which is the more appropriate at a particular point in time. When one compares these candidates with those proposed when a gender marking is present (bottom part of the figure), three main findings emerge. First, the stimulus word appears as a candidate sooner (during the second gate instead of the third); second, there are fewer candidate types proposed (16 vs. 22 ); and third, all the word candidates are feminine. (There is one "no answer," $\emptyset$, and one incomplete word, pla__). Not a single candidate is masculine, even when it would be a better choice at different points in time. For example, the masculine word plat (pronounced /pla/) is never proposed in the gender-present condition (where the article preceding joli(e) is the feminine "la"), but it is a strong candidate in the gender-absent condition.

We further investigated these findings by examining the number and the gender of all the proposed candidates for each of the 24 words of the study. For the number of candidates, we counted, for each word, the pro- posed candidate types at five points during the left-toright presentation of the word: $0 \%, 25 \%, 50 \%, 75 \%$, and $100 \%$ of the WTW. For the three middle percentages, we took the gates whose durations (expressed as a percentage of WTW) were closest to the percentages we were looking for. Thus, if one gate corresponded to $22 \%$ WTW, and the next corresponded to $29 \%$ WTW, we took the former for the $25 \%$ point. Figure 3 presents the mean number of proposed candidate types as a function of the position in the word and the gender-marking condition (present or absent). At the beginning of the word, when very little information about it had been heard (apart from some coarticulatory information), the same number of candidates were proposed in the two conditions. Even though the listener knew the gender of the noun in the gender-present condition, the potential pool of candidates was still too high (either $55 \%$ or $45 \%$ of the words in the internal lexicon, depending on the gender marking given) and, hence, there were almost as many candidates as there are subjects. As more of the stimulus word was heard in the gender-present condition, the 


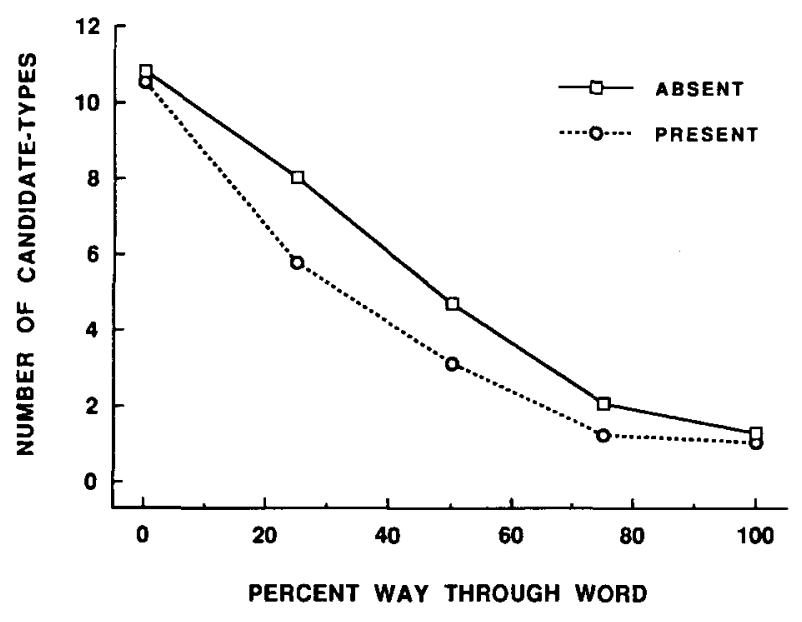

Figure 3. Mean number of candidate types proposed as a function of the position in the word (expressed as a percentage of the way through) and the condition: gender marking present (circles) and gender marking absent (squares). Each point is based on 24 words.

number of candidates decreased more quickly than in the gender-absent condition. The interplay of gender information and bottom-up information reduced the number of word candidates quite substantially. Finally, the two functions met again toward the end of the word because, by that time, whatever the condition, the word had been isolated. An analysis of variance by subjects confirmed this pattern. A main effect was found for condition $[F(1,23)=15.80, p<.001]$ and for percentage of WTW $[F(4,92)=220.66, p<.001]$, and there was a significant interaction between them $[F(4,92)=$ $7.94, p<.001]$. An a posteriori test (Tukey's $H S D$, Kirk, 1967) showed that the number of candidates proposed in the two conditions was significantly different at the $25 \%$ and $50 \%$ points, but not at the other positions $(0 \%$, $75 \%$, and $100 \%$ ).

To provide an analysis of the gender of the proposed candidates, we tabulated the candidate tokens for each word at each gate. Although we also examined candidate types, we preferred the token approach in this analysis, because it reflects more clearly the operations involved in the recognition of a lexical item. We did not take into account the items for which no gender classification could be made-that is, "no answers" (1.6\% of all responses) and unclassifiable items such as incomplete words, nonwords, and words that belonged to another syntactic class ( $0.4 \%$ of all responses). We were left with $98 \%$ of the responses $(4,773$ tokens in all), and for these we counted the number that did not share their stimulus word's gender. For example, if the stimulus word was plage (a feminine word), we put nom, plat, plastic, plateau, and so on (all masculine candidates) into the "wrong-gender category."

The results showed that a large proportion of candidate tokens did not share the gender of the stimulus word when the gender marking was absent $(27.12 \%)$, but not a single candidate had the wrong gender when the gender was marked in the preceding article. At first sight, the percentage obtained when gender marking was absent is rather low (one would expect some figure closer to $50 \%$, because the French lexicon is divided up more or less equally into masculine and feminine words), but it can be explained in part by the fact that the phonology and morphology of a word can sometimes give a clue about its gender. For example, words ending in "-age" are predominantly masculine, whereas words ending in "-ette" are overwhelmingly feminine (Tucker, Lambert, Rigault, \& Segalowitz, 1968). Another reason is that we included in the count the tokens that corresponded to the stimulus word (i.e., the correct answers given after the isolation point). When we performed a count by word type, we found a percentage closer to the one expected: $44.91 \%$. Whatever the procedure used, however, it is clear that, in the presence of gender marking, no word candidate ever has the wrong gender. This appears to indicate that gender marking has a very strong effect on the selection of candidates. When gender is marked on the article (and we can probably extend this finding to other words, such as pronouns and adjectives), only the nouns that share that gender are potential candidates, but when it is not marked in this way, nouns of both genders are candidates.

Before further discussing this finding, we will present a second experiment, which was aimed at obtaining converging evidence for the effect obtained.

\section{EXPERIMENT 2}

In this experiment, subjects were asked to make a lexical decision on nouns that were preceded either with an appropriate gender marking (carried by an article) or without a gender marking (absence of the article). Because of the results from Experiment 1, we expected reaction times to be significantly faster when the nouns were preceded by an appropriate marking.

\section{Method}

Subjects. Twenty-four native, French-speaking students of the University of Neuchâtel (Switzerland), with no reported speech or hearing defects, served individually. None of them had participated in Experiment 1.

Materials. We used the same stimuli from Experiment 1 (see the Appendix). Each of the 24 words was paired with an equal number of nonwords on length and consonant onset. All 48 items were once again embedded in the sentence, "J'ai vu un(e) joli(e) samedi" (I saw a nice___ on Saturday) and were

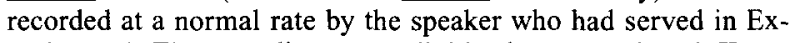
periment 1 . The recordings were digitized on a Macintosh II at a sampling rate of $22 \mathrm{kHz}$ with the Sound Designer II package. Two sets of experimental stimuli were prepared. Each set contained one of two sequences for each word (or nonword): "joli(e)

(gender marking absent) or "un/une joli(e) ____" (gender marking present). The sets contained as many words as nonwords and as many words that were preceded with the article as words that were not. Both sets had the same nonword phrases. The order of presentation of words and nonwords was the same in each set. A 5 -sec interstimulus interval separated the phrases, and a short, 
$1000-\mathrm{Hz}$ tone was placed at the onset of the noun on the right channel, for timing purposes.

Procedure. Each set of experimental stimuli was presented over headphones to a different group of subjects ( 12 subjects per group). The subjects were asked to listen to each phrase and decide if the noun was a word or a nonword by pressing the "mot" (word) or "nonmot" (nonword) key in front of them, as quickly as possible. The subjects practiced the task before listening to the stimuli. Reaction times were recorded with a Hewlett-Packard universal counter (HP 5315), which was started by the tone placed on the right channel and stopped by the keypress.

Data analysis. Only the reaction times to words were analyzed. When errors occurred $(4.17 \%$ of the total $)$, the times were replaced individually, by subject, with the subject's mean reaction time.

\section{Results and Discussion}

Figure 4 presents lexical decision times as a function of gender marking (absent and present). As can be seen, the subjects were slower, on average, when gender marking was absent than when it was present (629 and $586 \mathrm{msec}$, respectively). This $43-\mathrm{msec}$ difference was highly significant by words $[t(23)=4.16, p<.001]$ and by subjects $[t(23)=5.08, p<.001]$ and confirms the results obtained in the first experiment.

Analysis by word length and word gender. Even though each word was its own control in the two experiments (i.e., presented with and without an article), it is nevertheless interesting to examine the results as a function of word length and word gender. The question we asked is whether the gender-marking effect exists for both one- and two-syllable words as well as for masculine and feminine nouns. To determine this, we performed a number of subanalyses on the data obtained in the two experiments. Because these analyses used a reduced set of data and were thus more sensitive to individual data points, we decided to exclude any word for which more than half of its values were missing. This in-

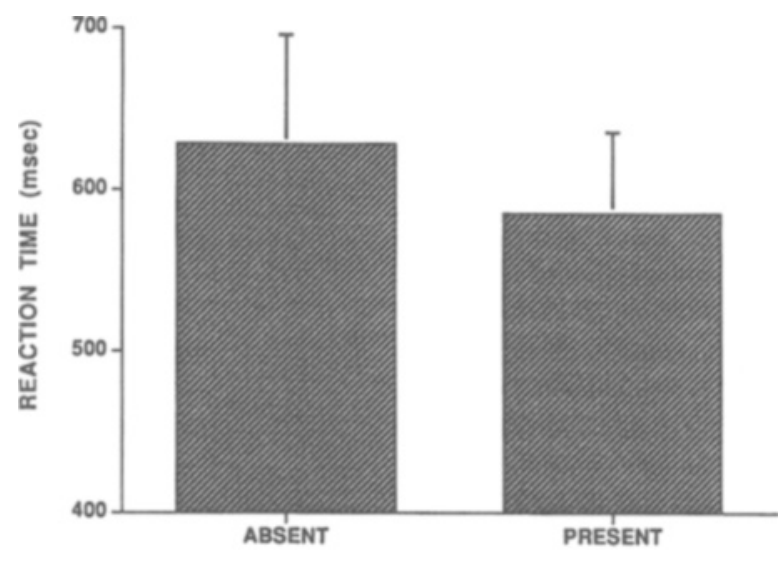

GENDER MARKING

Figure 4. Lexical decision response times to nouns as a function of the gender marking (absent and present) carried by the preceding article. Each mean is based on 288 observations. Error bars represent +1 standard deviation.

volved just one word, bois (wood)-a one-syllable masculine noun that was isolated by only 2 subjects in the gender-absent condition of Experiment 1. Thus, the analyses for the one-syllable and masculine words were based on 11 words, and those for the two-syllable and feminine words were based on 12 words. As in the global analyses, the isolation points, confidence ratings, and reaction times for the gender-absent and gender-present conditions were compared for each level of word length and word gender.

The results are presented in Table 1 . The results for word length show that one-syllable words had a gendermarking effect on each of the three measures. Admittedly, the $t$ values are lower than those in the main analy-

Table 1

Gender-Marking Effect as a Function of Word Length (One and Two Syllables) and Word Gender (Masculine and Feminine) for Each of the Measures

in Experiments 1 and 2

\begin{tabular}{|c|c|c|c|c|c|}
\hline Measure & $\begin{array}{c}\text { Gender Marking } \\
\text { Absent }\end{array}$ & $\begin{array}{c}\text { Gender Marking } \\
\text { Present } \\
\end{array}$ & $t$ Value & $\begin{array}{c}\text { Degrees of } \\
\text { Freedom }\end{array}$ & $p<$ \\
\hline \multicolumn{6}{|c|}{ Word Length (One Syllable) } \\
\hline Isolation point & 66.27 & 57.26 & 2.48 & 10 & .05 \\
\hline Confidence rating & 9.35 & 9.78 & 2.50 & 10 & .05 \\
\hline Reaction time* & 601 & 558 & 2.52 & 10 & .05 \\
\hline \multicolumn{6}{|c|}{ Word Length (Two Syllables) } \\
\hline Isolation point & 55.67 & 43.67 & 3.15 & 11 & .01 \\
\hline Confidence rating & 9.69 & 9.97 & 1.47 & 11 & n.s. \\
\hline Reaction time & 648 & 609 & 2.86 & 11 & .01 \\
\hline \multicolumn{6}{|c|}{ Word Gender (Masculine) } \\
\hline Isolation point & 59.82 & 52.0 & 2.36 & 10 & .05 \\
\hline Confidence rating & 9.51 & 9.85 & 2.14 & 10 & .05 \\
\hline Reaction time & 622 & 574 & 2.81 & 10 & .01 \\
\hline \multicolumn{6}{|c|}{ Word Gender (Feminine) } \\
\hline Isolation point & 61.58 & 48.58 & 3.32 & 11 & .01 \\
\hline Confidence rating & 9.54 & 9.91 & 1.80 & 11 & .05 \\
\hline Reaction time & 629 & 594 & 2.58 & 11 & .05 \\
\hline
\end{tabular}

*In milliseconds 
ses, but this is largely due to the fact that there were fewer words tested (11 vs. 24). For two-syllable words, a gender-marking effect was found with isolation points and reaction times, but not with confidence ratings. This is probably due to a ceiling effect obtained with the longer words; by the time the subjects heard the ends of these words, not only had they isolated them, but they had also reached a near-perfect level of confidence, whatever the context. This is clearly apparent in this experiment, in which very high ratings were found for twosyllable words in the gender-absent and gender-present conditions (9.69 and 9.97, respectively). As for word gender, all the subanalyses showed a main effect-for masculine as well as for feminine words. We can conclude from this that gender marking is a robust effect that can be found with words that differ in length and in gender.

\section{GENERAL DISCUSSION}

The present experiments have allowed us to answer the question we asked at the beginning of the paperwhether there is any evidence that the gender marking found on words, such as articles, affects the lexical access of the following nouns. The results we obtained with two very different tasks, gating and lexical decision, clearly showed the importance of gender marking. In the experiment with gating, the presence of gender marking on the article produced an earlier isolation point for the following noun, greater confidence at the end of the word, and candidates that all shared the preceding article's gender. In the lexical decision experiment, the absence of gender marking produced significantly longer reaction times than did its presence. Subanalyses by word length and word gender showed the robustness of the effect. We can conclude from this that gender marking can be added to the already long list of factors, such as frequency, length, uniqueness point, neighborhood size and frequency, syntactic, semantic, and pragmatic constraints, and so on, which account for the time it takes to identify a word. By comparing the absence of gender marking (the baseline) with its presence, we were also able to show that the effect is facilitatory. Further study is needed to determine whether it is also inhibitory, although unpublished data obtained in our laboratory seems to show that this is the case.

Although we have been able to find evidence for what appears to be a lexical effect, we cannot exclude the fact that it may also be a syntactic effect. In defense of a purely lexical effect, current interactive activation models, such as McClelland and Elman's (1986) TRACE model, would have little problem accounting for our results. When a word carrying a gender marking is identified, it activates all the nouns in the internal lexicon that share the same gender (without automatically inhibiting other words that could appear after it). An alternative to this would be that the gender feature of the preceding word activates all the nouns with that same feature. Ac- tivation facilitates the noun's recognition (see the isolation points, confidence ratings, and candidates proposed in the first study) and renders a metalinguistic task, such as lexical decision, easier.

An alternative explanation involves both the lexical and syntactic processing modules. The lexical module undertakes the recognition of the two words in question (e.g., an article and a noun) and the syntactic module "checks" to make sure that the gender agreement rule is respected. Although this account is not inconsistent with what takes place when lexical decision is done on the second of two words presented together (see Forster, 1979), it may not totally explain some of our gating results. First, the subjects needed significantly less of a word in order to isolate it when it was preceded by an article carrying gender information, and second, the proposed candidates differed greatly from those obtained in other types of context. Thus, it has been found that when syntactic and semantic constraints are manipulated in gating studies (e.g., Grosjean, 1980; Tyler \& Wessels, 1983), the candidates proposed at the early gates do not always correspond to what is expected. For example, even though the context may predict a noun, some early candidates may correspond to a different word class. Here, however, gender marking behaved differently, in the sense that only the nouns that corresponded to the article's gender were proposed, even at the very early gates. Even though an output mechanism or decision process under the tight control of the syntactic module could perhaps explain this finding, it is no less interesting that slippage exists in other situations and not with gender marking.

Future studies with such tasks as cross-modal priming may help locate the effect, but they will probably not resolve the lexical versus syntactic debate completely. Indeed, it may well turn out that the gender-marking effect is a lexical effect and a syntactic effect. For example, it could be that nouns that belong to a particular gender category and that are spoken in isolation prime one another (thereby showing a strictly lexical effect). We may also find that other words that are marked for gender (articles, adjectives, etc.) prime nouns of the same gender, as we have proposed. As for the syntactic effect, one may find that the recognition of a word whose gender has been announced well in advance of the word itself is the result of both lexical and syntactic processing. Thus, in the sentence, "Construite au début du siècle, cette table est un chef-d'oeuvre" (Built at the turn of the century, this table is a masterpiece), the feminine inflection on the past participle construite announces a feminine noun that will be accessed several words later. In this case, we can hypothesize that the syntactic module checks to make sure that the past participle and the later-occurring noun agree in gender.

Whatever the final explanation of the gender-marking effect-lexical, syntactic, or both-it is interesting to ask why it is present, since it reduces the set of candidates "only" by about half (at least in French). One pos- 
sible answer is that listeners will use whatever cues are available to them to facilitate lexical access. Some languages offer gender marking, others offer tones, others offer stress, and so on. These language-specific variables will interact with general variables, such as frequency, uniqueness point, syntactic and semantic constraints, and so on, to render lexical access optimal (Marslen-Wilson, 1987). As children acquire a language, they become sensitive to its specificities and learn to use them during processing. This in turn may explain why gender is maintained in certain languages when there is no real linguistic reason for this to happen (Jim Gee, personal communication, 1983).

In the future, researchers will need to locate the gender-marking effect and determine whether it is both facilitatory and inhibitory. In addition, they will want to examine how gender information that is given by the phonology and morphology of a word affects its recognition (see Bates, Devescovi, Pizzamiglio, D'Amico, \& Hernandez, 1994) and how this particular effect interacts with the one obtained when gender information is conveyed by another word (as in the present study). It will also be necessary to study whether the different types of words that carry gender marking (articles, pronouns, adjectives, etc.) produce different effects, and what combining these words does to the overall effect, as when a noun is preceded by an article as well as an adjective. Furthermore, the effect needs to be studied in other gender-carrying languages. Preliminary research on German and Italian (Bates et al., 1994; Friederici \& Schriefers, 1993) shows a gender effect, but this does not seem to be the case in Dutch (Berkum, personal communication, 1993). Finally, it will be interesting to study how bilinguals use gender information during lexical access when one of their languages does not have gender marking and the other does, or when both of their languages carry gender marking but sometimes give contradictory markings, such as feminine "die Vase" (the vase) in German and masculine "le vase" in French, or masculine "el cacahuete" in Spanish and feminine "la cacahuète" in French.

\section{REFERENCES}

Bates, E., Devescovi, A., Pizzamiglio, L., D'Amico, S., \& HernanDEZ, A. (1994). Gender and lexical access in Italian. Unpublished manuscript, University of California, San Diego, Center for Research in Language.

Bradley, D., \& Forster, K. (1987). A reader's view of listening. Cognition, 25, 103-134.

COLÉ, P., \& SÉGUI, J. (1994). Grammatical incongruency and vocabulary types. Memory \& Cognition, 22, 387-394.

Content, A., Mousty, P., \& Radeau, M. (1990). BRUleX: Une base de données lexicales informatisées pour le français écrit et parlé. [BRLLEX: A computerized lexical data base of written and spoken French]. L'Année Psychologique, 90, 551-566.

Corbett, G. (1991). Gender. Cambridge: Cambridge University Press.

Cutler, A., Mehler, J., Norris, D., \& SéGui, J. (1986). The syllable's differing role in the segmentation of French and English. Journal of Memory \& Language, 25, 385-400.

Forster, K. (1976). Accessing the mental lexicon. In R. Wales \&
E. Walker (Eds.), New approaches to language mechanism (pp. 257287). Amsterdam: North-Holland.

FORSTER, K. (1979). Levels of processing and the structure of the language processor. In W. Cooper \& E. Walker (Eds.), Sentence processing (pp. 27-85). Hillsdale, NJ: Erlbaum.

Friederici, A., \& SChriefERs, H. (1993). Semantic and morphosyntactic context effects on word recognition: The influence of peripheral and central processing variables. Unpublished manuscript, Freie Universität, Berlin, Cognitive Science Laboratory.

GrosJean, F. (1980). Spoken word recognition processes and the gating paradigm. Perception \& Psychophysics, 28, 267-283.

Grosjean, F., \& Gee, J. (1987). Prosodic structure and spoken word recognition. Cognition, 25, 135-155.

Juilland, A., Brodin, D., \& Davidovitch, C. (1970). Frequency dictionary of French words. The Hague: Mouton.

KIRK, R. (1967). Experimental design: Procedures for the behavioral sciences. Belmont, CA: Brooks/Cole.

Le Robert oral-ecrit. (1989). Paris: Les dictionnaires Le Robert.

MARSLEN-Wilson, W. (1984). Function and process in spoken word recognition. In H. Bouma \& D. Bouhuis (Eds.), Attention and performance $X$ (pp. 125-150). Hillsdale, NJ: Erlbaum.

MARSLEN-WILSON, W. (1987). Functional parallelism in spoken word recognition. Cognition, 25, 71-102.

MARSLEN-WILSON, W. (1990). Activation, competition, and frequency in lexical access. In G. Altmann (Ed.), Cognitive models of speech processing (pp. 148-172). Cambridge, MA: MIT Press.

MCClelland, J., \& ElmaN, J. (1986). The TRACE model of speech perception. Cognitive Psychology, 18, 1-86.

MORTON, J. (1970). A functional model for memory. In D. Norman (Ed.), Models of human memory (pp. 203-254). New York: Academic Press.

RADEAU, M., \& MoraIS, J. (1990). The effect of the uniqueness point in shadowing spoken words. Speech Communication, 9, 155-164.

Radeau, M., Mousty, P., \& Bertelson, P. (1989). The effect of the uniqueness point in spoken-word recognition. Psychological Research, 51, 123-128.

SÉGUI, J. (1989a). L'accès au lexique: Données expérimentales et modèles. In Calliope (Ed.), La parole et son traitement automatique (pp. 215-231). Paris: Masson.

SÉGui, J. (1989b). Traitement de la parole et lexique. In P. Lecocq \& J. Ségui (Eds.), L'accès lexical (pp. 13-28). Lille: Presses Universitaires de Lille.

SÉGui, J., Dupoux, E., \& Mehler, J. (1990). The role of the syllable in speech segmentation, phoneme identification and lexical access. In G. Altmann (Ed.), Cognitive models of speech processing (pp. 263-280). Cambridge, MA: MIT Press.

Tucker, G., Lambert, W., Rigault, A., \& Segalowitz, N. (1968). A psychological investigation of French speakers' skill with grammatical gender. Journal of Verbal Learning \& Verbal Behavior, 7, 312-316.

TYLER, L. K., \& Wessels, J. (1983). Quantifying contextual contributions to word-recognition processes. Perception \& Psychophysics, 34, 409-420.

TYLER, L. K., \& WeSSELS, J. (1985). Is gating an on-line task? Evidence from naming latency data. Perception \& Psychophysics, 38, 217-222.

Webster's ninth new collegiate dictionary. (1991). Springfield, MA: Merriam-Webster.

Wioland, F., Brock, G., \& Metz-Lutz, M. (1990). Speech perception during spoken-language processing in French: How comprehension processes interact with the perception of on-going speech Clinical Linguistics \& Phonetics, 4, 303-317.

\section{NOTES}

1. The closest study we have found is one by Colé and Ségui (1994), who used number and gender to investigate the role of grammatical congruity in the processing of written French. Double lexical and primed lexical tasks were used to show that agreement congruity takes place faster for closed-class than for open-class words.

2. Gating is particularly useful for assessing how much acoustic/ phonetic information is needed for a word to be identified correctly. It 
also gives some insight into the word recognition process. It has often been asked whether gating is an on-line task, such as monitoring, lexical decision, or naming. Given that subjects are not usually put under time pressure to respond during normal uses of gating (but see Tyler \& Wessels, 1985), it is different by nature. However, gating does appear to reflect some of the processes that take place on line-that is, during normal language processing. On the one hand, gating results (in particular, isolation-point data) correlate highly with data obtained with tasks such as word monitoring, shadowing, naming, and even cross-modal repetition priming (Grosjean, 1980; Marslen-Wilson, 1984, 1990; Tyler \& Wessels, 1985). On the other hand, numerous word recognition effects found with on-line tasks have been replicated with gating. Among these we find context, word frequency, word length, word stress, word inflection, competitor frequency and number, and coarticulation. The debate about the time course of these effects is still open in the literature. Autonomous models have many of them come in during a postaccess stage (Forster, 1976), whereas interactionist models question the very existence of this second stage and integrate the effects during the soleaccess stage (Grosjean \& Gee, 1987; McClelland \& Elman, 1986; Morton, 1970). Given that gating results correlate highly with data obtained with on-line tasks, that gating is sensitive to well-known word recognition effects, and that the debate on the level at which these effects occur is still continuing, it makes sense to use the paradigm, along with other tasks, to investigate lexical access. Gating can certainly tell us something about the final outcome of word recognition. Whether it can also do so about intermediary levels remains an empirical issue.
3. It should be noted that a noun phrase containing only an adjective and a noun (e.g., "jolie table") is grammatical in French as well as in English. One finds such phrases in appraisals and exclamations.

\section{APPENDIX}

The 24 Words Used in Experiments 1 and 2 and the Translations of Their Most Frequent Meanings (in Parentheses)

Masculine Nouns

$\quad$ One Syllable
MEUBLE (furniture)
COIN (corner)
MASQUE (mask)
PRINCE (prince)
SAC (sack)
BOIS (wood)

Two Syllables

CADEAU (present)

DÉCOR (scenery)

costume (costume)

CHÂTEAU (castle)

TISSU (cloth)

SOURIRE (smile)

Feminine Nouns

One Syllable
PLAGE (beach)
BOÎTE (box)
FERME (farm)
PLANTE (plant)
CHAISE (chair)
MONTRE (watch)

Two Syllables

CHAPELLE (chapel)

COLONNE (pillar)

MONTAGNE (mountain)

FORÊT (forest)

PRINCESSE (princess)

CAMPAGNE (country)

(Manuscript received April 1, 1993;

revision accepted for publication June $10,1994$. 